\title{
Minimally Invasive Dynamic Hip Screw Fixation for the treatment of stable Intertrochanteric Fractures of femur
}

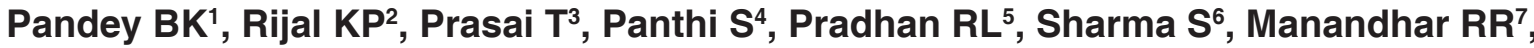 \\ Lakhey $\mathbf{S}^{8}$
}

${ }^{1}$ Bimal Kumar Pandey, Assistant Professor; ${ }^{2}$ Kiran Prasad Rijal, Professor; ${ }^{3}$ Tanup Prasai, Lecturer; ${ }^{4}$ Sagar Panthi, Orthopaedic Resident; ${ }^{5}$ Rabindra Lal Pradhan, Associate Professor; ${ }^{6}$ Sashmit Sharma, Lecturer; ${ }^{7}$ Rajeev Raj Manandhar, Assistant Professor; ${ }^{8}$ Shishir Lakhey, Professor; Department of Orthopaedics, Kathmandu Medical College Teaching Hospital, Kathmandu, Nepal.

\section{Abstract}

Background: Trochanteric fracture is the commonest fracture in elderly people. These fractures carry risks associated with prolonged immobility. Early fracture fixation allowing early mobilization of the patients is the aim of the treatment. Dynamic hip screw and plate remains the most common method for treating stable intertrochanteric fractures. Minimal invasive technique has advantages of less blood loss, minimal soft tissue dissection, early mobilization, lesser requirement of analgesics and shorter hospital stay.

Objectives: The study was done to evaluate the amount of intraoperative blood loss, reduction of postoperative haemoglobin, requirement of post-operative analgesics and days of postoperative hospital stay in the patients of stable intertrochanteric femur fracture treated with minimal invasive dynamic hip screw (MIDHS).

Methods: Twenty-five cases of stable intertrochanteric fractures of femur were treated with minimal invasive Dynamic hip screw technique. Average blood loss during surgery, reduction of postoperative haemoglobin, requirement of post-operative analgesics and total days of postoperative hospital stay were studied.

Results: Mean intraoperative blood loss was $53 \mathrm{ml}$, mean reduction of postoperative haemoglobin was $0.9 \mathrm{gm} / \mathrm{dl}$. Average wound size was of five $\mathrm{cm}$. Postoperative analgesic requirement was twice a day in an average and for five days. Mean hospital stay after surgery was five days.

Conclusion: Minimal invasive Dynamic hip screw is a safe technique having advantages of less blood loss, minimal soft tissue dissection, lesser requirement of post-operative analgesics and shorter hospital stay in treating stable intertrochanteric fractures.

Key words: Dynamic Hip Screw, Intertrochanteric fractures, Minimally invasive

\section{INTRODUCTION}

$\mathrm{T}$ rochanteric fracture of femur is one of the commonest fractures in elderly people ${ }^{1,2}$. This fracture carries risks associated with prolonged immobility. Early

\section{Address for correspondence:}

Dr Bimal Kumar Pandey

\section{Assistant Professor}

Department of Orthopaedics, Kathmandu Medical

College Teaching Hospital, Kathmandu, Nepal

E-mail: bimalpandey@ hotmail.com mobilization of the patients reduces the complications ${ }^{1}$. Early mobilization is only possible when stable fixation is achieved with less post-operative pain and when patients become haemodynamically stable. There are various methods of stable fixation such as sliding hip screw, intramedullary nail, trochanteric locking plate, fixed angle blade plate and dynamic condylar plate $^{1-3}$. Dynamic hip screw fixation remains one of the common methods of treatment in stable intertrochanteric fractures ${ }^{4-6}$. Minimal invasive surgeries result in reduction of postoperative pain and help in early mobilization of the patients. Minimal invasive dynamic hip screw (MIDHS) 
fixation has advantages of less blood loss, minimal soft tissue dissection, lesser requirement of post-operative analgesics and shorter hospital stay ${ }^{6-8}$. Hence this study was conducted to evaluate the outcome of MIDHS.

\section{METHODS}

This is a prospective study including 25 patients operated with MIDHS technique between May 2011 and July 2013 at Kathmandu Medical College Teaching Hospital with at least six months of follow up. All closed stable intertrochanteric fractures with AO (Arbeitsgemeinschaftfur Osteosynthesefragen) type A1.1 to A2.1 were included in the study. Patients with polytrauma, pathological fracture, unstable intertrochanteric fracture with AO type A2.2 to A3.3, compound fracture and failed closed reduction on fracture table were excluded from the study.

All operations were performed under spinal anaesthesia on fracture table. Fractures were reduced by closed manipulation and checked under image intensifier. A guide wire mounted in 135-degree guide plate was placed over anterior aspect of hip and checked in image intensifier in AP view (Figure 1). Plate was made aligned with the lateral border of femur and guide wire was aligned in lower half of femoral neck and head (Figure 2). Hence entry point of guide wire was marked in lateral aspect of thigh. About five $\mathrm{cm}$ of skin incision was made. Fascia lata and Vastus lateralis were incised by diathermy to minimize blood loss (Figure 3). Guide wire was inserted from lateral border of femur below 2.5 $\mathrm{cm}$ from trochanteric flair with the help of 135-degree angle guide. Correct placement of guide-wire was checked with image intensifier in AP and lateral views. Reaming was done with desired length. Hip screw was then inserted. Guide-wire was removed. Four-hole barrel plate was inserted through the wound in such a way that barrel faces laterally (Figure 4). After inserting the plate it was turned 180-degree and introduced over hip screw (Figure 5). In obese patients difficulties in inserting the barrel on hip screw were made easy with reintroducing guide-wire through the barrel plate. Plate was then fixed with femur shaft with four cortical screws. Compression screw was inserted. Fascia and subcutaneous tissues were sutured with absorbable suture andskin was closed with staples. No drain was inserted.
Intraoperative blood loss was measured with weighing of blood soaked gauze pieces. Specific gravity of red corpuscles is 1.0293 and of plasma 1.0270. Hence one $\mathrm{ml}$ of blood weighs one $\mathrm{gm}^{9}$.

Postoperative AP and lateral radiographs were obtained in the next day of surgery. Postoperative analgesic protocol was maintained. For the first 24 hours all the patients received injection Diclofenac $75 \mathrm{mg}$ intramuscular (deep gluteal) eight hourly. From 24 hours onward tablet Diclofenac $50 \mathrm{mg}$ was prescribed on requirement basis. Amount of analgesic consumption was noted.

Postoperative haemoglobin was measured after 24 hours of surgery and its value was compared with preoperative haemoglobin. The difference was noted.

Toe touch ambulation in walker was started from the first postoperative day. Patients were discharged from hospital once they were well ambulated. Sutures were removed in two weeks. Partial weight bearing ambulation was started in three weeks and full weight bearing ambulation was started in an average of three months. $\mathrm{AP}$ and lateral radiographs were obtained in three weeks, six weeks, three months and six months follow up. Duration for achieving radiological union was noted. Complications were recorded.

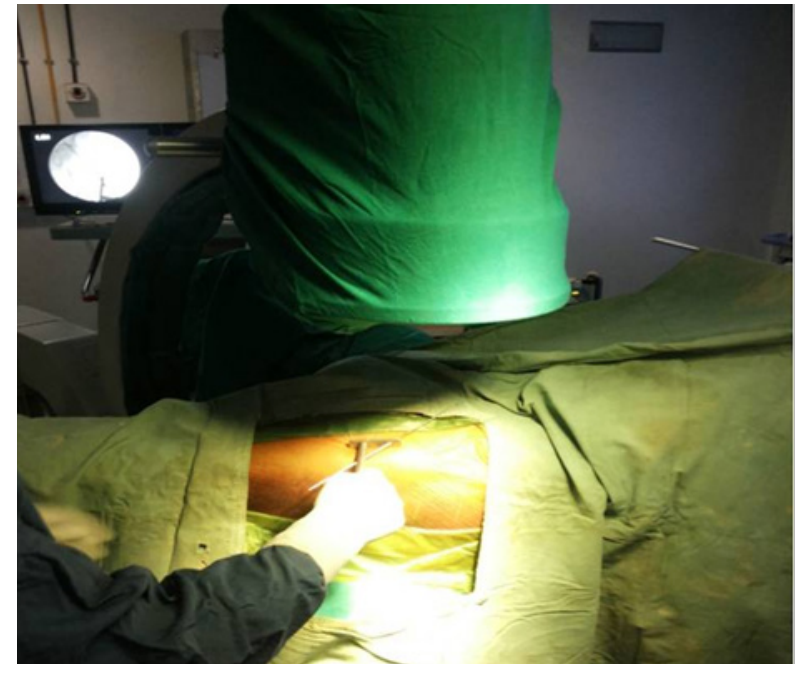

Figure 1: Incision site 


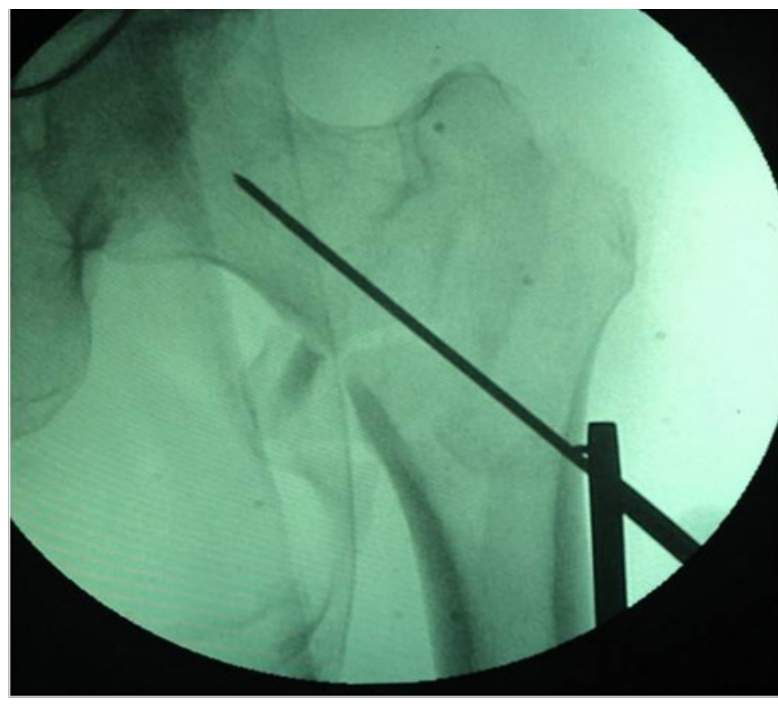

Figure 2: C-arm image to find out entry point

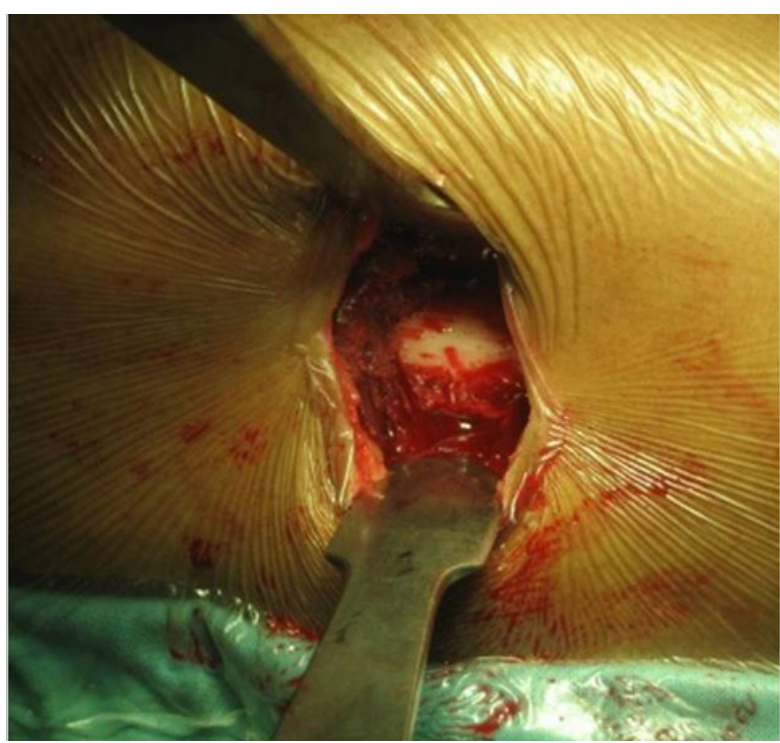

Figure 3: Guide wire entry point

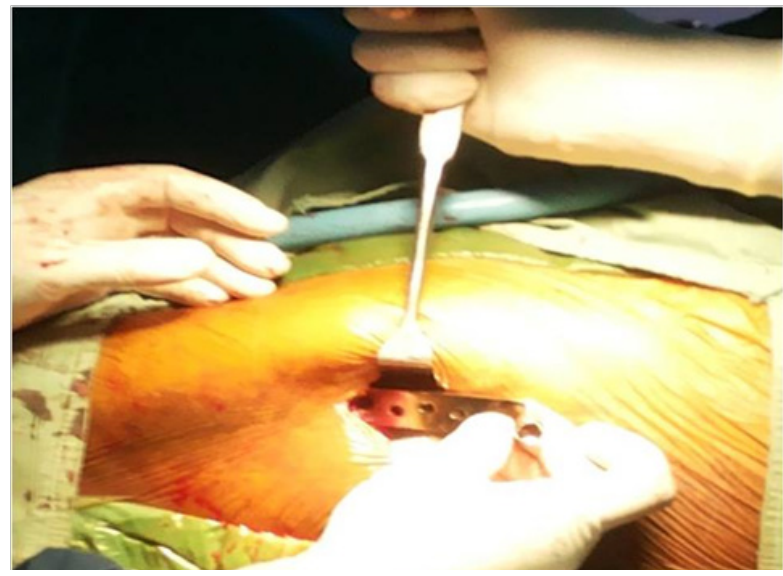

Figure 4: Insertion of barrel plate

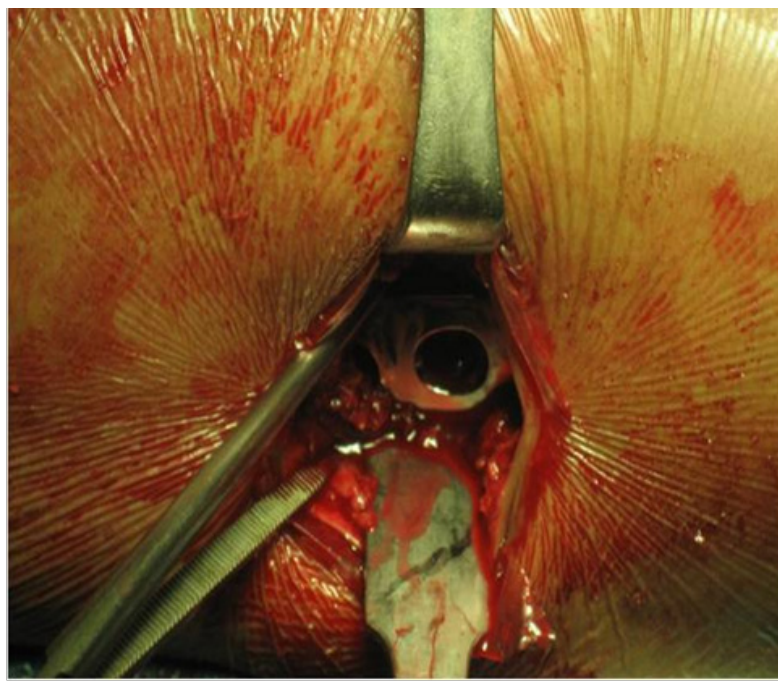

Figure 5: Insertion of barrel plate over hip screw

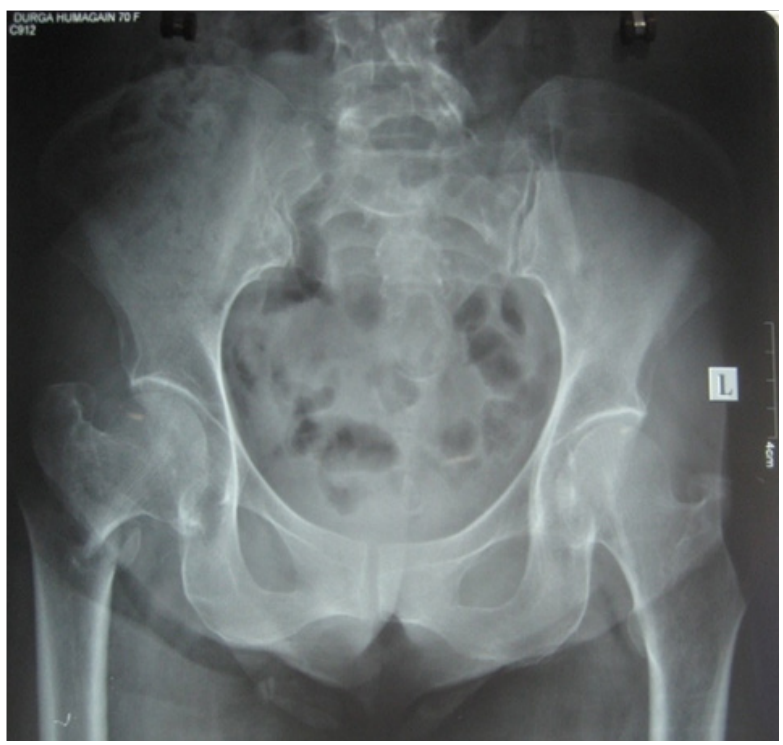

Figure 6: Preoperative X-ray of Pelvis AP view

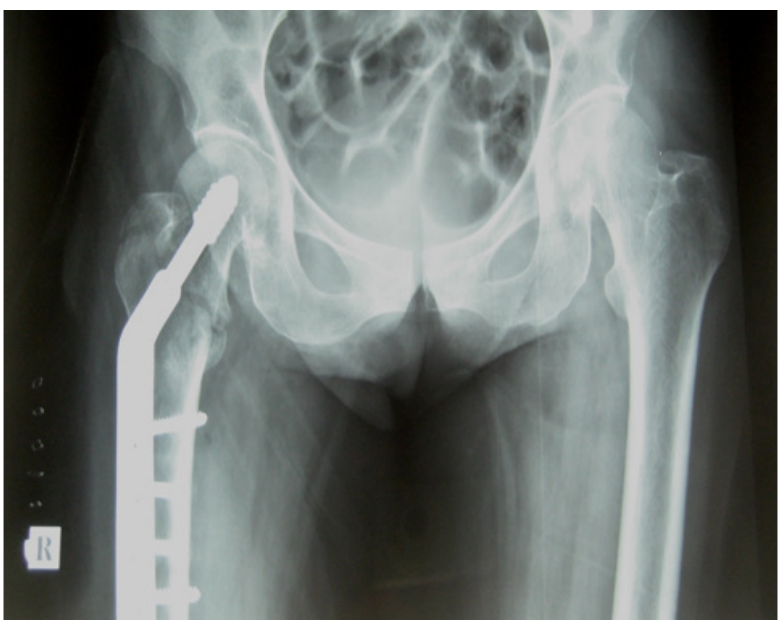

Figure 7: Postoperative X-ray Pelvis AP view 


\section{RESULTS}

Twenty-five patients with stable intertrochanteric fracture were followed up for at least six months. There were 15 male patients and 10 female. Average age of the patients was 73 years ranging from 60 years to 86 years. 14 fractures were in right side and 11 in left. Mean operating time was 50 minutes ranging from 40 to 60 minutes. Mean wound size was of five $\mathrm{cm}$.

Mean peroperative blood loss was $53 \mathrm{ml}$ (range: 43 $85 \mathrm{ml}$ ). Mean reduction of postoperative haemoglobin was $0.9 \mathrm{gm} / \mathrm{dl}$ ranging from 0.3 to $1.1 \mathrm{gm} / \mathrm{dl}$. Mean requirement of analgesics in postoperative period was for five days (three to seven days). Mean requirement of analgesics in a day was two times (one to three times). Mean operating time was $50 \mathrm{~min}(40-60 \mathrm{~min})$. Mean wound size was of five $\mathrm{cm}$. Mean hospital stay after surgery was five days (four to six days). All fractures united within three months. There were no surgery related complications.

\section{DISCUSSION}

Use of dynamic hip screw and plate remains one of the common methods for the treatment of intertrochanteric fracture of femur. This method provides rigid fixation and facilitates early mobilization of patients ${ }^{6,10}$.

There are several studies with good results using minimal invasive dynamic hip screw (MIDHS) for the treatment of stable intertrochanteric fracture of femur.

In MIDHS it has been found to have less peroperative blood loss than with conventional DHS (CDHS). It is thought to be due to less soft tissue dissection, less fracture exposure and incision being in the safer vascular zone $^{8,10,11}$. In our study amount of peroperative blood loss was $53 \mathrm{ml}(43-85 \mathrm{ml})$. In the study of Di Paola et al ${ }^{12}$ it was $41 \mathrm{ml}$. Little et $\mathrm{al}^{13}$ found $160 \mathrm{ml}$ of peroperative blood loss in conventional DHS. Houet $\mathrm{al}^{14}$ and Chua et al ${ }^{15}$ had an average of $283 \mathrm{ml}$ and $409 \mathrm{ml}$ of peroperative blood loss respectively with conventional DHS (CDHS). Reduction of postoperative haemoglobin was less in MIDHS than in conventional DHS in comparative studies of Wong et $\mathrm{al}^{6}$, Ho et $\mathrm{al}^{8}$ and Wang et $\mathrm{al}^{11}$ (Table 1). Less blood loss reduces the requirement of its transfusion and minimizes cardiovascular complications.
Table 1: Comparison of reduction of post-operative haemoglobin in various studies.

\begin{tabular}{lccc} 
Study & N & \multicolumn{2}{c}{ Hb reduction (g/dl) } \\
& & MIDHS & CDHS \\
Wong et al. (2009) & 66 & 1.4 & 2.6 \\
Ho et al. (2009) & 88 & 1.18 & 2.4 \\
Wang et al. (2010) & 97 & 1.3 & 3.4 \\
Our & 25 & 0.9 &
\end{tabular}

Table 2: Comparison of wound size in various studies.

\begin{tabular}{lcccc} 
Study & N & $\begin{array}{c}\text { Wound } \\
\text { size (cm) } \\
\text { MIDHS }\end{array}$ & $\begin{array}{c}\text { Barrel } \\
\text { CDHS }\end{array}$ \\
& & & \\
Wong et al. (2009) & 66 & 2.5 & & 4 hole \\
Ho et al. (2009) & 88 & 5 & 15 & 4 hole \\
Alobaid et al. (2004) & 48 & 3 & & 2 hole \\
Walia et al. (2010) & 25 & 3 & 2 hole \\
Our & 25 & 5 & 4 hole \\
\hline
\end{tabular}

Size of the wound has direct relation with post-operative pain and wound contamination. In our series we had wound size of an average five $\mathrm{cm}$ which is comparable with the wound size of Hoet $\mathrm{al}^{8}$. Wong et $\mathrm{al}^{6}$ and Alobaid et $\mathrm{al}^{7}$ had wound size of $2.5 \mathrm{~cm}$ and Walia et al had of three $\mathrm{cm}$. In the study of $\mathrm{Ho}$ et al the wound size in conventional DHS was of $15 \mathrm{~cm}$. To minimize wound size Alobaid et al and Waliaet al ${ }^{16}$ used two hole DHS and concluded that two hole DHS plate using minimally invasive technique gives as good results as a regular DHS done with a longer incision and plate in stable intertrochanteric fractures ${ }^{17}$. In our study we used four hole DHS (Table 2).

In our study patients received $75 \mathrm{mg}$ of intramuscular injection of Diclofenac eight hourly in postoperative period for 24 hours and then afterward tablet Diclofenac $50 \mathrm{mg}$ in oral form as per required with maximum of three times a day. Average requirement of tablet Diclofenac in postoperative period was 10 tablets. Average total days of analgesic required were five days. Wong et al ${ }^{6}$ in their study found that the amount of postoperative analgesic required were $8.6 \mathrm{mg}$ of pethidine and 5.4 tablets in MIDHS whereas $48.4 \mathrm{mg}$ of pethidine and 8.6 tablets in conventional DHS. They concluded the requirement of postoperative analgesics were significantly less in 
MIDHS than CDHS. Similarly in their study Alobaid et $\mathrm{al}^{7}$ patients need $15.1 \mathrm{mg}$ of Morphine, $169 \mathrm{~g}$ of Codeine and $1.9 \mathrm{~g}$ of Acetaminophen as postoperative analgesics in MIDHS group whereas $25.2 \mathrm{mg}$ of Morphine, $209 \mathrm{~g}$ of Codeine and $5.4 \mathrm{~g}$ of Acetaminophen in CDHS group.

Lee et $\mathrm{al}^{10}$ found that the length of hospital stay after surgery was 5.4 days in MIDHS group and 8.8 days in CDHS group. Wang et al ${ }^{11}$ had 5.7 days of postoperative length of hospital stay in MIDHS and 7.9 days in CDHS groups. In the study of Hoet al ${ }^{8}$ he found that the average length of hospital stay of patients in MIDHS group was 12.1 days and in CDHS group was 23.3 days. In our study average length of postoperative hospital stay

\section{REFERENCES}

1. Kyle RF, Gustilo RB, Premer RF. Analysis of six hundred and twenty-two intertrochanteric hip fractures. J Bone Joint Surg Am. 1979;61(2):21621.

2. LaVelle DG. Fractures of hip. In: Canale ST, editor. Campbell's operative orthopaedics. Philadelphia, PA, USA: Mosby/Elsevier; 2008. p. 2873-938.

3. Dhamangaonkar AC, Joshi D, Goregaonkar AB, Tawari AA. Proximal femoral locking plate versus dynamic hip screw for unstable intertrochanteric femoral fractures. JOrthopSurg (Hong Kong). 2013;21(3):317-22.

4. Bolhofner BR, Russo PR, Carmen B. Results of intertrochanteric femur fractures treated with a 135-degree sliding screw with a two hole side plate. J Orthop Trauma. 1999;13(1):5-8.

5. Zuckerman JD, Skovron ML, Koval KJ, Aharonoff G, Frankel VH. Postoperative complications and mortality associated with operative delay in older patients who have a fracture of the hip. J Bone Joint Surg Am. 1995;77:1551-6.

6. Wong TC, Chiu Y, Tsang WL, Leung WY, Yeung $\mathrm{SH}$. A double-blind, prospective, randomized, controlled clinical trial of minimally invasive dynamic hip screw fixation of intertrochanteric fractures. Injury. 2009;40(4):422-27.

7. Alobaid A, Harvey EJ, Elder GM,Lander P, Guy P, Reindl R. Minimally invasive dynamic hip screw: prospective randomized trial of two techniques of insertion of a standard dynamic fixation device. $J$ Orthop Trauma. 2004;18(4):207-12.

8. Ho M, Garau G, Walley G, Oliva F, Panni AS, Longo UG, Maffulli N. Minimally invasive dynamic hip screw for fixation of hip fractures. Int Orthop. 2009;33(2):555-60. was Five days which is similar with the studies of Lee et $\mathrm{al}^{10}$ and Wang et al ${ }^{11}$. Less postoperative pain, ability to ambulate patient early and less complication lessen length of hospital stay reducing burden to caregivers and reduces the treatment cost significantly.

\section{CONCLUSION}

Minimal invasive dynamic hip screw fixation technique is effective and safe method in treating stable intertrochanteric fractures and it reduces intraoperative blood loss, postoperative analgesic use and length of hospital stay.

9. Thomton JA. Estimation of blood loss during surgery. Ann R Coll Surg Engl. 1963 Sep;33(3):16474.

10. Lee YS, Huang HL, Lo TY, Huang CR. Dynamic hip screw in the treatment of intertrochanteric fractures: a comparision of two fixation methods. Int Orthop. 2007;31(5):683-88.

11. Wang JP, Yang TF, Kong QQ, Liu SJ, Xiao H, Liu HZ. Minimally invasive technique versus conventional technique of dynamaic hip screw for intertrochanteric femoral fractures. Orthop Trauma Surg. 2010;130(5):613-20.

12. DiPaola M, Rozbruch SR, Helfet DL. Minimal incision technique using a two-hole plate for fixation of stable intertrochanteric hip fractures. Orthopaedics. 2004;27:270-74.

13. Little NJ, Verma V, Fernando C, Elliott DS, Khaleel A. A prospective trial comparing the Holland nail with the dynamic hip screw in the treatment of intertrochanteric fractures of the hip. J Bone Joint Surg Br. 2008 Aug;90(8):1073-78.

14. Hou GJ, Zhou F, Zhang ZS, Ji HQ, Tian Y. Analysis of the blood loss in perioperative period of femoral intertrochanteric fractures in old patients treated with different internal fixations. Beijing DaXueXue Boa. 2013 Oct 18;45(5):738-41.

15. Chua YP, Kwan MK, Saw A. Operative treatment of trochanteric fractures with dynamic hip screw is perioperative blood transfusion needed? Med $\mathrm{J}$ Malaysia. $2005 \mathrm{Jul} ; 60 \mathrm{C}: 78-82$.

16. Walia JPS, Gupta AC, Singh M, Walia SK, Singh S. $\mathrm{Pb} J$ Orthop. 2010;12(1):12-13.

17. McLoughlin SW, Wheeler DL, Rider J, Bolhofner B (2000). Biomechanical evaluation of the dynamic hip screw with two- and four-hole side plates. $J$ Orthop Trauma. 2000;14:318-23. 